\title{
Detección de cambios en la cobertura de la tierra de un sector del occidente de Honduras Período 1991 - 2006
}

María Cristina Pineda de Carías, Vilma Lorena Ochoa, Rafael Enríque Corrales*

\section{RESUMEN}

Disponer de un conjunto de imágenes clasificadas por cobertura de la tierra de varios años, habiendo utilizado la misma metodología científica para todas ellas, hace que los datos y los cambios detectados en cuanto a incrementos 0 decrementos de cualquiera de las clases sean homogéneos, comparables y por tanto más confiables. El objetivo de este trabajo fue detectar, a partir del estudio de cuatro imágenes satelitales LandSat de diferentes fechas, los principales cambios en la cobertura de la tierra de un sector del occidente de Honduras, en un periodo de quince años que abarcó, siete y medio años antes y después del Huracán Mitch. La metodología empleada incluyó, desde la selección de las imágenes de fechas y características apropiadas; el pre procesamiento para realizar correcciones geométricas y radiométricas; la delimitación del área de estudio y acopio de información relevante de la zona; la obtención de una leyenda basada en el Sistema de Clasificación de Cobertura de la Tierra de la FAO-UNEP; la realización de clasificación supervisada de las cuatro imágenes; la verificación de resultados mediante el uso de radiometría de campo y de técnicas estadísticas; terminando con el análisis multitemporal para la detección de cambios.

Como principales resultados: se comparó la reflectancia calculada a partir de las imágenes LandSat con la reflectancia medida con un radiómetro de campo; se elaboró cartografía de la clasificación supervisada de los años de 1991, 1995, 2003 y 2006; y se cuantificaron los cambios en la cobertura de la tierra, antes y después de Mitch. Conclusión importante fue, el marcado avance de la frontera agrícola a expensas de la disminución de la cobertura de bosques del sector, acompañado por otro lado de la recuperación del bosque, especialmente de pino, a partir de coberturas de matorrales, pastos y suelo desnudo.

\section{Palabras clave: Percepción Remota, clasificación supervisada, radiometría de campo, análisis multitemporal.}

\footnotetext{
Universidad Nacional Autónoma de Honduras. Facultad de Ciencias Espaciales.

mcpinedacarias@gmail.com, vl_ochoa@yahoo.com.mx, rafa504@yahoo.com
} 


\section{ABSTRACT}

Having a set of images of several years classified by land cover, having used the same scientific methodology for all of them, does that the information and the changes detected as for increases or decreases of anyone of the classes are homogeneous, comparable and therefore more reliable. The aim of this work was to detect, from the study of four LandSat satellite images of different dates, the main changes in the land cover of a sector of western Honduras, in a period of fifteen years that spanned seven and a half years before and after Hurricane Mitch. The methodology included, from the selection of the images of appropriate characteristics and dates, the pre processing for geometric and radiometric corrections, the delimitation of the study area and collection of relevant information of the zone, obtaining a legend based on the Land Cover Classification System of the FAO-UNEP, conducting a supervised classification of the four images, the verification of results by using field radiometry and statistical techniques, finishing with multitemporal analysis to detect changes.

As main results: compared the reflectance calculated from LandSat imagery with the reflectance measured with a field radiometer; mapping the supervised classification of the years of 1991, 1995, 2003 and 2006; and changes of land cover were quantified before and after Mitch. Important finding was the marked advance of the agricultural frontier at the expense of the decrease of the coverage of forests of the sector, accompanied on the other hand by the recovery of forest, especially of pine, from coverage of shrubs, pastures and bare soil.

\section{Key words: Remote sensing, supervised classification, field radiometry, multitemporal analysis.}




\section{INTRODUCCIÓN}

La superficie de la tierra está cambiando rápidamente, a escalas locales, regionales, nacionales y globales, con significativas repercusiones para la gente, las economías, y el ambiente. Algunos de los cambios tienen causas naturales, tales como los incendios forestales o huracanes, mientras que otros cambios sobre la tierra, tales como la extracción de recursos, prácticas agrícolas, y crecimiento urbano, son procesos humanos inducidos. Hay otro tipo de cambios que son una combinación de factores naturales y humanos inducidos; los deslizamientos y las inundaciones, por ejemplo, son fundamentalmente procesos naturales que son generalmente intensificados o acelerados por el uso y prácticas humanas. Cualquiera que sea su causa, los cambios en la superficie de la tierra tienen impactos profundos en el ambiente y en la economía (United States Geological Survey, USGS, 2012).

En la segunda mitad de octubre a primeros días del mes de noviembre de 1998 ocurrió el huracán Mitch. Fue un devastador y uno de los más mortales huracanes responsable de la muerte de unas nueve mil personas predominantemente por las lluvias y deslizamientos inducidos en porciones de Centroamérica, principalmente en Honduras y Nicaragua (Guiney \& Lawrence, 1999). En los territorios hondureños, Mitch pasó primero como un huracán, degradándose a tormenta y luego a depresión tropical. Sus huellas sin embargo dejaron intensas marcas en la cobertura de la tierra, donde las inundaciones y particularmente los deslizamientos se observaron en todo el territorio nacional.

Alrededor de las fechas de ocurrencia del Huracán Mitch, en la Clasificación de los países por Índice de Desarrollo Humano (IDH), para el año de 1995 Honduras ocupó el lugar 119 de 174 países alcanzando un valor de 0.573, que la colocó dentro del grupo de países que no habían logrado traducir la prosperidad económica en una vida mejor para su pueblo (Programa de las Naciones Unidas para el Desarrollo (PNUD), 1998). Para el año 2004 estos indicadores mejoraron un poco, ocupando Honduras el lugar 117 de 177 países, y un valor de IDH de 0.683 (Programa de las Naciones Unidas para el Desarrollo (PNUD), 2006).

La aplicación del IDH al estudio de los departamentos y municipios del país, resalta las diferencias entre las distintas unidades territoriales administrativas, permitiendo analizar el impacto de la inequidad espacial en el logro de metas nacionales de desarrollo. Así por ejemplo, para el año 1996 los valores del IDH para cada uno de los 18 departamentos de Honduras revelaron la existencia de 12 departamentos con un nivel medio de desarrollo humano (categoría en la que se encontraba 
Honduras), en tanto que los otros seis departamentos se encontraron en un nivel bajo de desarrollo. En el lugar más bajo con menos de 0.500 se ubicaron los seis departamentos que desde el punto de vista espacial, representaron el grupo de menor desarrollo humano: Ocotepeque: 0.482, La Paz: 0.465, Santa Bárbara: 0.432, Copán: 0.430, Intibucá: 0.416 y Lempira: 0.368. Para el año 2004 los valores de IDH para estos departamentos se incrementaron: Ocotepeque: 0.600, La Paz: 0.610, Santa Bárbara: 0.597, Copán: 0.578, Intibucá: 0.582, y Lempira: 0.554, manteniéndose la misma tendencia de menor desarrollo para este grupo de departamentos del sector occidental de Honduras (Programa de las Naciones Unidas para el Desarrollo Honduras, 2006).

Preocupados por el bajo desarrollo del sector occidental de Honduras, quisimos hacer un análisis espacio temporal de la zona. Nos encontramos con el problema, que lo hicimos de nuestro estudio, que no se contaba en Honduras con suficiente información geoespacial ligada a un conocimiento confiable de la cobertura y uso de la tierra del sector occidental para un período mayor de una década que permitiera asegurar, como es que se han incrementado o como es que se han disminuido las coberturas vegetales de bosques de latifoliados o de coníferas, de arbustos o pastos, en relación con cualquier tendencia marcada por el avance de la frontera agrícola, por el uso intensivo de los recursos del suelo, o por variaciones del patrón de asentamiento urbano con la alteración o modificación de ciclos de producción y crecimiento de los recursos naturales.

De las tecnologías de la información geográfica la percepción remota (0 teledetección), es conocida por el amplio rango de aplicaciones y experiencias en proyectos de investigación que han demostrado con su uso la validez de determinadas metodologías, siendo fuente primaria de información en campos como la cartografía de la cobertura de la tierra (Chuvieco Salinero, 2008). La metodología incluye el manejo de las bases para la interpretación de imágenes remotas, el análisis digital de las imágenes para aplicar correcciones geométricas y radiométricas, la extracción de información temática particularmente para realizar la clasificación digital y la aplicación de las técnicas de análisis multitemporal. La verificación de los resultados toma un papel relevante, cuandojunto al empleo de técnicas estadísticas para medidas del error, se incorpora además el uso de la radiometría de campo.

Tendencias para clasificar la cobertura y el uso de la tierra de diferentes zonas del Planeta han sido conocidas a nivel mundial en las últimas cuatro décadas, coincidiendo éstas con la generación de datos de percepción remota tales como las imágenes de los sensores de los satélites LandSat TM y EMT+, SPOT y otros 
similares. De los diferentes sistemas de clasificación más conocidos, especial atención han merecido el Sistema de Clasificación por Cobertura y Uso de la Tierra para uso con datos de sensores remotos propuesto por Anderson y otros del Servicio Geológico de los Estados Unidos (Anderson, Hardy, Roach,\& Witmer, 1976); el Sistema de Clasificación CORINE de Cobertura de la Tierra de la Unión Europea (Agencia Europea del Medio Ambiente, 1995); y el Sistema de Clasificación de la cobertura de la tierra propuesto por la Agencia de las Naciones Unidas para la Alimentación y la Agricultura, FAO-UNEP (Di Gregorio, 2005). Al comparar estas tres metodologías de clasificación se advierte que, aunque el objetivo de clasificación aparentemente podría ser el mismo, la realidad es que por su alcance, ha sido diferente en cada caso. El primer sistema ha buscado clasificar toda la extensión de un país, los Estados Unidos. El segundo sistema ha buscado clasificar la extensión de todos y cada uno de los países de un continente: Europa. Con el tercer sistema se ha buscado desarrollar un sistema para clasificar a todo el Planeta.

El Sistema de Clasificación por Cobertura de la Tierra (LCCS) de la FAO-UNEP, ha sido desarrollado para satisfacer la necesidad de acceder a información confiable mejorada y estandarizada de la cobertura de la tierra y de los cambios en la cobertura de la tierra. Es un sistema de clasificación comprensivo, estandarizado a priori diseñado para llenar requerimientos específicos de los usuarios, y creado para ejercicios de mapeo independientes de la escala o medios usados para hacer los mapas. Permite comparar las clases de cobertura de la tierra independiente de la fuente de datos, disciplina temática o país.

Disponer de un conjunto de imágenes clasificadas por cobertura de la tierra de varios años, habiendo utilizado la misma metodología científica para todas ellas, hace que los datos y los cambios detectados en cuanto a incrementos 0 decrementos de cualquiera de las clases sean homogéneos, comparables y por tanto más confiables.

La Radiometría de Campo abarca el uso de técnicas para la detección y el análisis de las características espectrales y biofísicas de los objetos de la superficie terrestre en su entorno natural cercano (campo próximo). Complementa las técnicas de la Percepción Remota y proporciona datos para desarrollar y probar modelos que describen relaciones entre la reflectividad espectral direccional de diferentes superficies y sus atributos biofísicos; permite la caracterización de la reflectividad de las superficies utilizadas en la calibración de sensores en aviones 0 en plataformas orbitales; permite la estimación de los efectos atmosféricos a partir de la correlación de los datos de campo con los remotamente detectados; y sirve 
como herramienta de predicción. Los dispositivos que utiliza son los radiómetros de campo que miden de forma precisa y extensa, la respuesta espectral de las cubiertas terrestres en ausencia de los efectos atmosféricos (Arquero, Martínez, \& Gonzalo, 2003).

De las aportaciones más destacadas de la Percepción Remota al estudio del medio ambiente se puede mencionar su capacidad para seguir procesos dinámicos. Al utilizar información adquirida por un sensor que estable y repetitivamente orbita a la tierra, las imágenes de satélite constituyen una fuente valiosísima para estudiar los cambios que se producen en la superficie terrestre, ya sean estos debidos al ciclo estacional de las cubiertas, a catástrofes naturales, ó a alteraciones de origen humano. En el seguimiento de la dinámica de un determinado fenómeno conviene distinguir, entre la rapidez con que se produce, de la pervivencia que implica el cambio (Chuvieco Salinero, 2008).

El objetivo de este trabajó fue detectar, a partir del estudio de cuatro imágenes LandSat de diferentes fechas, los principales cambios en la cobertura de la tierra de un sector del occidente de Honduras, en un período de quince años que abarcó, siete y medio años antes y después del Huracán Mitch. Metodológicamente el trabajo se enmarcó en la Percepción Remota y la Radiometría de Campo utilizando, desde la selección de las imágenes de fechas y características apropiadas; el pre procesamiento para realizar correcciones geométricas y radiométricas; la delimitación del área de estudio y acopio de información relevante de la zona; la obtención de una leyenda basada en el Sistema de Clasificación de Cobertura de la Tierra de la FAO-UNEP; la realización de clasificación supervisada de la cobertura de la tierra de las cuatro imágenes seleccionadas; la verificación de resultados mediante el uso de radiometría de campo y de técnicas estadísticas; terminando con el análisis multitemporal para la detección de cambios.

Cuatro fueron los principales resultados de este trabajo. Elaboramos una leyenda usando el Sistema de Clasificación de Cobertura de la Tierra de FAO/UNEP; y la cartografía temática de la clasificación supervisada de los años de 1991, 1995, 2003 y 2006. Comparamos la reflectancia calculada a partir de las imágenes del Satélite LandSat con la reflectancia medida con un radiómetro de campo en la zona de estudio, lo que permitió establecer comparaciones entre el comportamiento de diferentes tipos de cubierta en diferentes fechas. Elaboramos cartografía de los cambios ocurridos en la cobertura de la tierra del sector occidental de Honduras escogido como área de estudio, y cuantificamos estos cambios para fechas antes y después de Mitch. 
Conclusión importante fue, el marcado avance de la frontera agrícola a expensas de la disminución de la cobertura de bosques del sector; acompañado por otro lado de la recuperación del bosque, especialmente de pino, a partir de las coberturas de matorrales, pastos y suelo desnudo. Este trabajo fue presentado en el VI Congreso de Investigación Científica de la Universidad Nacional Autónoma de Honduras, celebrado en la Ciudad Universitaria de Tegucigalpa, Honduras, del 6 al 9 de agosto de 2012.

\section{DATOSY METODOLOGÍA}

\subsection{Los Datos}

Para realizar este trabajo escogimos imágenes obtenidas por LandSat, un satélite que ha orbitado la tierra desde la década 1970 a una altura estable de más de 700 kilómetros. Para abarcar el sector occidental de Honduras, y de acuerdo con el Sistema de Referencia del Mundo (WRS) de LandSat, seleccionamos imágenes con número de trayectoria y fila P019R050 (United States Geological Survey, 2012). Tomando como referencia 1998 el año de ocurrencia de Mitch, buscamos imágenes satelitales alrededor de ésta fecha para abarcar un período de quince años; procuramos que las imágenes reunieran requisitos de muy bajo porcentaje de cobertura de nubes. Como resultado seleccionados cuatro imágenes de las cuales, las dos primeras fueron obtenidas por el Satélite Landsat-5: L5_1991/Marzo/04 y L5_1995/Febrero/11; las otras dos por el Satélite Landsat 7: L7__2003/Abril/14 y L7_2006/Marzo/21. La resolución espacial de las imágenes era de 28.5 metros.

Por el año de obtención de las imágenes seleccionadas, éstas quedaron comprendiendo siete y medio años antes e igual período de tiempo después de la fecha del huracán Mitch. Por el día y el mes del año de cada una de las imágenes, el período quedó incluido entre los meses de febrero a abril, coincidiendo con la época más seca del año del país.

Para el almacenamiento, manejo y procesamiento de los datos utilizamos un programa para procesamiento y análisis de imágenes satelitales instalado en una computadora personal. Las imágenes, originalmente en formato GEOTIFF fueron convertidas a formato IMAGINE (.img). Desde el punto de vista espectraly aunque las imágenes estaban conformadas por todas sus bandas, escogimos la combinación de bandas: 4, 3, 2. Este rango espectral de bandas (de 0.52 a $0.90 \mu \mathrm{m}$ ) se ajustaba al rango del radiómetro de campo utilizado que adelante detallamos. 


\subsection{Metodología}

La metodología utilizada abarcó las seis fases que se describen a continuación.

\subsubsection{Pre-procesamiento de las imágenes}

Realizamos dos tipos de correcciones: geométricas y radiométricas.

Correcciones Geométricas. Se removieron las distorsiones geométricas y se georreferenciaron de la misma manera las cuatro imágenes. Los parámetros de proyección fueron los siguientes: Datum de Referencia: WGS 84; Elipsoide de Referencia: WGS 84; Opción de remuestreo: vecino más cercano; Proyección de mapeo: UTM, con parámetros para la Zona 16. Se trabajó con coordenadas UTM, Zona 16.

Correcciones Radiométricas. Las correcciones radiométricas las hicimos en tres partes. Una calibración para convertir los números digitales (DN) de la matriz de datos originales de cada imagen a magnitudes físicas de radiancia. El cálculo de reflectancias en el tope de laatmósfera (TOA). El cálculo de la reflectancia en la superficie de la tierra mediante la corrección de la absorción y dispersión molecular (Rayleigh) atmosférica.

El objetivo general de las correcciones atmosféricas es convertir los valores obtenidos por un sensor remoto en valores de reflectancia en superficie. Estos valores son necesarios cuando se trata de usar los datos satelitales para el análisis cuantitativo de las propiedades biofísicas de los elementos de la superficie terrestre e identificar y evaluar los procesos que en ella ocurren mediante la comparación de diferentes escenas en estudios temporales (Sistema de Información de Biodiversidad, 2005).

\subsubsection{Delimitación del área de estudio y acopio de información relevante}

Dentro de la imagen completa LandSat escogimos como área de estudio un sector que fuera representativo del paisaje del Occidente de Honduras, con altas montañas, coberturas boscosas, ríos y áreas urbanas y agrícolas. Seleccionamos un cuadrado de 23 kilómetros de lado localizado entre las coordenadas: $301,084 \mathrm{~m}$ Ey $1627,720 \mathrm{~m} \mathrm{~N}$ (esquina superior izquierda), 324,115m E y 1614,692m N (esquina inferior derecha), con unárea de 53,160 hectáreas.

El área seleccionada cubre el lado sureste del Departamento de Copán (Municipios de Santa Rosa de Copán, San Juan de Opoa, Cucuyagua y San Pedro), y la parte 
noroeste del Departamento de Lempira (Municipios de Lepaera, Talgua, Las Flores y Gracias). En el cuadrante noroeste sobresale la ciudad de Santa Rosa, cabecera del Departamento de Copán y la más poblada del área de estudio, con 28,292 habitantes según el Censo Nacional de 2001. En el cuadrante sureste sobresale la ladera norte de la Montaña de Celaque, importante zona protegida del occidente de Honduras declarada Parque Nacional por su cobertura de bosques de pino, mixto y latifoliado. En el borde sur del área de estudio esta montaña alcanza una altura de 1,400 m.s.n.m.

La parte central elárea de estudio es atravesada por el Río Higuito que corre de este a oeste hasta unirse con el Río Grande de Mejocote, juntos forman el Río Jicatuyo que corre de sur a norte. Los ríos Higuito y Jicatuyo ambos sirven de línea divisoria entre los departamentos de Copán y Lempira. También estos ríos separan, hacia el norte, parte de la Cordillera Central donde se ubica una meseta de unos 1,000 metros de altura, donde está situada la ciudad de Santa Rosa de Copán. Del otro lado se encuentra parte de la Cordillera del Sur que comprende la Sierra y la Montaña de Celaque. De éstas montañas nacen innumerables ríos y riachuelos que se unen a los ríos principales (Pineda Portillo, 2008). La zona es reconocida por su agricultura tradicional donde se cultiva café, piña, maíz, frijoles, hortalizas.

\subsubsection{Obtención de una leyenda basada en el Sistema de Clasificación escogido}

El Sistema de Clasificación por Cobertura de la Tierra de la FAO-UNEP es capaz de describir el rango completo de características de la cobertura de la tierra. Para aplicarlo a un área particular, hay que seleccionar ciertas clases para construir una leyenda siguiendo un proceso que comprende dos fases principales, una Fase Dicotómica inicial, y otra Jerárquica Modular. La Fase Dicotómica inicial permite distinguir, en tres niveles, cada vez entre dos clases. El primer nivel distingue las clases en áreas principalmente con vegetación de las que están en áreas sin vegetación; dentro de estas, en un segundo nivel, entre clasesen áreas terrestres de acuáticas o regularmente inundadas; hasta llegar al tercer nivel en el que se pueden distinguir, siempre en opciones de dos, entre ocho posibles clases.

En la Fase Jerárquica Modular, se utiliza un conjunto de clasificadores arreglados jerárquicamente en módulos que ayudan a tallar las clases de la mejor manera que se ajusten al tipo de cobertura biofísica observada sobre la superficie de la tierra (cobertura de la tierra). Antes de aplicar el Sistema de Clasificación por Cobertura de la Tierra, nos familiarizamos con el área de estudio para reconocer los diferentes tipos de cobertura. 


\subsubsection{Clasificación del área de estudio para las cuatro fechas seleccionadas}

La clasificación es el proceso por medio del cual se arreglan los pixeles en un número finito de clases individuales o categorías de datos, a partir de los valores de los datos. Si un pixel satisface un cierto conjunto de criterios, entonces el pixel es asignado a la clase que le corresponde (Leica Geosystems, 2012).

La técnica escogida fue la clasificación supervisada, que nos permitió controlar el proceso para crear, manejar, evaluar y editar las firmas espectrales. Para definir las firmas espectrales, primero seleccionamos pequeños polígonos dentro del área de estudio a los que asignamos un color y un nombre de acuerdo a la clase. Este proceso lo repetimos para cada una de las siete clases de la leyenda. Las pequeñas áreas fueron seleccionadas en base al conocimiento del área de estudio y a los criterios de clasificación de cada clase. Cada vez que seleccionamos una firma espectral la evaluamos. El proceso lo repetimos hasta quedar satisfechos, procurando alcanzar la máxima separabilidad entre las firmas. Luego realizamos el proceso de clasificación supervisada utilizando reglas de decisión paramétricas.

\subsubsection{Validación de resultados por radiometría de campo y técnicas estadísticas}

Radiometría de campo. Los datos de campo próximo los obtuvimos con un radiómetro de campo portátil (FieldSpec HandHeld Spectroradiometer ASD) que funciona conectado a una computadora portátil en la que previamente habíamos instalado un programa especializado que sirvió de interfase gráfica para la toma y almacenamiento de los datos. El radiómetro mide espectros en el rango Visible/Infrarrojo Cercano (VNIR) con longitudes de onda entre 325 a 1075 m, utilizando un arreglo de fotodiodos de silicio de 512 canales sobrepuesto en filtros ordenados y separados. Cada canal, por el mismo, es un detector individual que está posicionado geométricamente para recibir la luz dentro de un angosto ancho de banda nominal de $1.6 \mathrm{~nm}$. La resolución espectral del radiómetro (FWHM de una sola línea de emisión) es de aproximadamente $3 \mathrm{~nm}$ a alrededor de $700 \mathrm{~nm}$ (Analytical Spectral Devices, Inc, 2003).

Para el registro de la respuesta espectral realizamos tomas con el radiómetro en posición vertical y un ángulo acimutal relativo al Sol de $180^{\circ}$ (de cara al Sol). El radiómetro tiene un campo de visión cónica (FOV) que subtiende un ángulo de unos $25^{\circ}$, colocado a una altura de $20 \mathrm{~cm}$ abarcó un área de $62 \mathrm{~cm}^{2}$ (equivalentes a un rectángulo de $7.85 \mathrm{~cm}$ de lado). Los valores obtenidos con el radiómetro 
correspondieron a la reflectancia, tanto del panel blanco de referencia como de las muestras objeto de estudio. Para cada medición, tomamospor lo menos 10 muestras de datos, las que fueron corregidas por corriente de oscuridad y blanco de referencia.

Para que la interpretación de los datos remotos (LandSat) respecto a los datos próximos (radiómetro) fuera fiable, seleccionamos muestras de clases distinguibles y representativas. Seleccionamos y medimos muestras de pastos, que de acuerdo al sistema de clasificación usado habíamos llamado pastos permanentes y pastos cambiantes; medimos también muestras de agricultura, de piña y maíz seco. En la Figura 1 se muestran las curvas de reflectancia obtenidas.

Figura 1. Curvas de Reflectancia medidas con el radiómetro de campo.

Fecha: 22/Marzo/2012

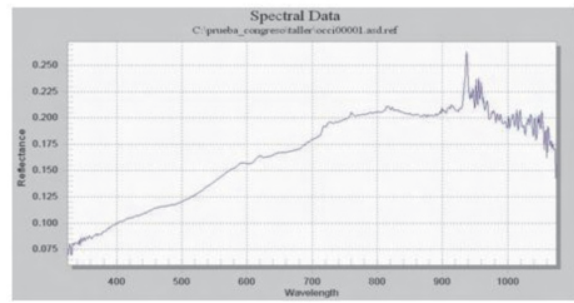

Pastos - permanente

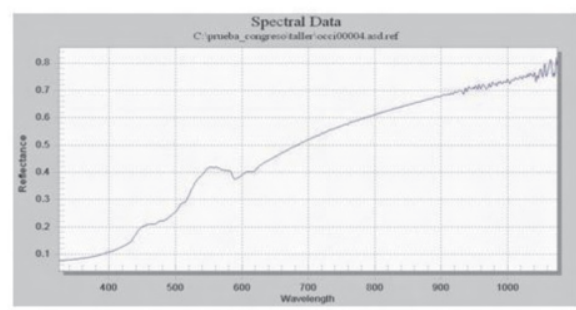

Agricultura - Piña

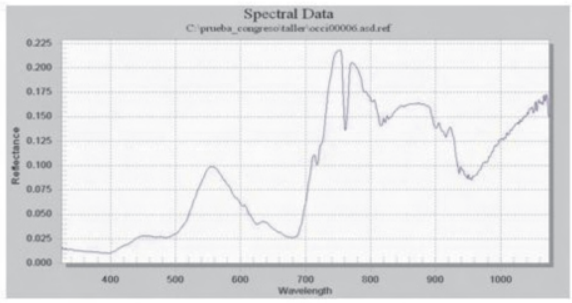

Pastos - cambiante

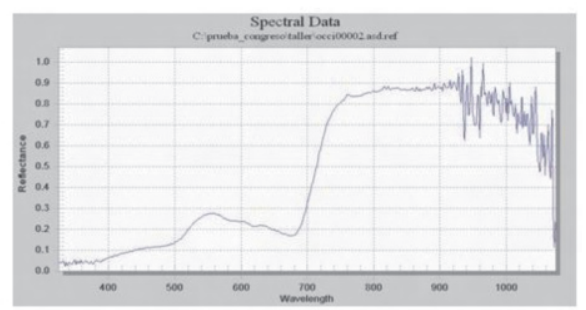

Agricultura - Maiz seco

Validación de resultados por técnicas estadísticas. Para la validación de los resultados seleccionamos aleatoriamente una muestra simple de 192 puntos, cuantificada para estimar con el $95 \%$ de probabilidad el error de cada imagen clasificada, suponiendo que los aciertos podían ser del 85\% y el máximo error permitido de $5 \%$. En cada imagen, para cada punto de verificación asignamos el valor de la clase, tomando en cuenta fotografías aéreas, cartografía básica, mapas temáticos de la zona, los datos de las visitas de campo y documentación de la zona. 
Hicimos un análisis estadístico de los datos de referencia y los datos clasificados, generando una matriz de error o confusión, determinando también la exactitud total y las estadísticas Kappa. Para las cuatro imágenes clasificadas, la exactitud global de clasificación fue mayor de 93\%, y la Estadística Global Kappa mayor de 0.92.

\subsubsection{Análisis multitemporal y detección de los cambios}

Elaboramos dos mapas de cambios de la cobertura de la tierra a partir de la comparación de dos imágenes de diferentes fechas a la vez. Por un lado comparamos las dos imágenes antes de Mitch: 1991 y 1995; y por otro, comparamos las otras dos imágenes de después de Mitch: 2003 y 2006. Para cuantificar todos los cambios posibles, conformamos una matriz cuadrada de siete por siete, que tenía en las filas las clases de la fecha más temprana y en las columnas las clases de la fecha más tardía. Los cuarenta y nueve valores de cambio obtenidos los agrupamos en tres categorías para mostrar:

- Decrementos (rojo): cuando los cambios ocurrieron por variación de la clase de bosque mixto a coberturas de pino, matorral, pasto, agricultura, urbano o suelo desnudo; 0 de pino a coberturas de matorral, pasto, agricultura, urbano o suelo desnudo.

- Sin cambio (blanco): cuando las coberturas se mantuvieron estables en las dosimágenes.

- Incrementos (verde): cuando los cambios ocurrieron por conversión de las coberturas de pino, matorrales, pastos, agricultura o suelo desnudo a bosque mixto; o de matorrales, pastos, agricultura o suelo desnudo a pino.

\section{RESULTADOS}

\subsection{Construcción de la Leyenda utilizando el Sistema de Clasificación FAO- UNEP}

Con nuestro conocimiento del área de estudio, y utilizando el software especializado del Sistema de Clasificación de Cobertura de la Tierra FAO/UNEP (Versión 2) obtuvimos las siete clases que describimos a continuación.

En la Fase Dicotómica: Áreas de vegetación terrestre natural y seminatural, utilizando los clasificadores de la Fase Modular definimos las siguientes tres clases: 


\section{Clase - Nombre de Usuario: Bosque Mixto}

Distinguimos que es una clase compuesta de dos tipos de cobertura:

a) Cobertura A: árboles; de cobertura cerrada; altura: > 30 - 14m; distribución espacial: fragmentada; hoja ancha. Por ejemplo, roble, encino, laurel.

b) Cobertura B: árboles; de cobertura dispersa de 15 a 4\%; altura: > 30 -14m; hoja acicular. Por ejemplo, pinos.

Clase - Nombre Estándar: Clase mixta. Arboles altos de hoja ancha, fragmentada; con árboles altos de hoja acicular dispersos [(20-10)-4\%].

\section{Clase - Nombre de Usuario: Bosque de Pino}

Distinguimos que es una clase de un solo tipo de cobertura:

a) Cobertura A: bosque; de cobertura abierta de 65 a 15\%; altura: >30 - 14m: hoja acicular. Por ejemplo: pinos.

Clase-Nombre estándar: Bosque. Arboleda de hoja acicular.

\section{Clase- Nombre de Usuario: Matorral}

Distinguimos que es una clase de un solo tipo de cobertura:

a) Cobertura A: arbustos; de cobertura abierta de 65 a 15\%; altura: de 5 a 0.5m; hojaancha.

Clase-Nombre Estándar: Arbustos. Arbustos de hoja ancha de medianos a altos.

En la Fase Dicotómica: Áreas terrestres cultivadas y manejadas, utilizando los clasificadores de la Fase Modular definimos las siguientes dos clases:

\section{Clase- Nombre de Usuario: Pastos}

Distinguimos que es una clase de dos tipos de cobertura:

a) Cobertura A: herbácea; en un campo de grande a mediano; distribución espacial continua; con un cultivo adicional, herbáceo terrestre, simultáneo; regado con agua de lluvia; cultivo de rotación o cambiante, parte de un proceso agrícola.

b) Cobertura B: herbácea; en un campo de grande a mediano; distribución espacial continua; con un cultivo adicional, herbáceo terrestre, simultáneo; 
regada con agua de lluvia; cultivo permanente.

Clase - Nombre Estándar: Clase mixta. Cultivo cambiante de herbáceas cosechadas (un cultivo adicional) (cultivo herbáceo terrestre con período simultáneo); con Áreas permanentemente cultivadas con cultivos herbáceos (un cultivo adicional) (cultivo herbáceo con período simultáneo).

\section{Clase- Nombre de Usuario: Agricultura}

Distinguimos que es una clase de por lo menos cinco tipos de cobertura:

a) Cobertura A: Arbustos, en huertos u otro tipo de plantación; en campo de grande a mediano; distribución espacial continua; con dos cultivos adicionales de arbustos simultáneos; regado con lluvia; cultivo permanente. Por ejemplo, café.

b) Cobertura B: arbustos, plantación; en campo de grande a mediano; distribución espacial continua; cultivo simple; regado con lluvia; cultivo permanente. Por ejemplo, piñas.

c) Cobertura C: gramíneas; en campo de grande a mediano; distribución espacial continua; cultivo simple; regado con lluvia; cultivo de rotación o cambiante. Por ejemplo, maíz.

d) Cobertura D: No gramínea; en campo de grande a mediano; distribución continua; al menos dos cultivos adicionales, herbáceos terrestres, simultáneos; $\quad$ regado con lluvia; cultivo de rotación o cambiante. Por ejemplo, hortalizas.

e) Cobertura E: herbácea; en campo de grande a mediano; distribución espacial continua; con dos cultivos adicionales, herbáceos terrestres, simultáneos; regado con lluvia; cultivo en barbecho, resultado de una etapa de proceso agrícola.

Clase - Nombre Estándar: Clase mixta. Área permanentemente cultivada con arbustos cultivados con agua de lluvia (dos cultivos de arbustos con períodos simultáneos) cobertura cultivada en huerto; con Área permanentemente cultivada con arbustos cultivados con agua de lluvia, cobertura cultivada en plantación; con cultivos cambiantes de gramíneas cultivadas; con cultivos cambiantes de no gramíneas (dos cultivos adicionales) (dos cultivos herbáceos terrestres ambos de períodos simultáneos); con cultivos de herbáceas (dos cultivos adicionales) (dos cultivos herbáceos terrestres ambos con períodos simultáneos) con sistema de barbecho.

En la Fase Dicotómica: Áreas de superficies artificiales y asociadas, utilizando los clasificadores de la Fase Modular definimos la siguiente clase: 


\section{Clase- Nombre de Usuario: Urbano}

Distinguimos que es una clase de un solo tipo de cobertura:

a) Cobertura A: superficie construida, no lineal, área urbana.

Clase - Nombre Estándar: Áreas construidas. Área(s) urbana(s).

En la Fase Dicotómica: Áreas desnudas, utilizando los clasificadores de la Fase Modular definimos la siguiente clase:

\section{Clase- Nombre de Usuario: Suelo desnudo}

Distinguimos que es una clase de un solo tipo de cobertura:

a) Cobertura A: superficie no consolidada, suelo desnudo y otro material no consolidado; pedregoso (40-5\%).

Clase - Nombre Estándar: Áreas desnudas no consolidadas. Suelo desnudo pedregoso y/u otro(s) material(es) no consolidado(s).

Con las siete clases resultantes conformamos la leyenda. El nombre y el color asignado a cada una de las siete clases fueron los siguientes: bosque mixto (verde oscuro); arboleda de pino (verde); matorral (café); pastos mixtos (naranja); agricultura mixta (amarillo); urbano (rojo); suelo desnudo (blanco).

Por los estándares de publicación requerido en el Proyecto, determinamos que para efectos de mapeo la escala sería 1:150,000; con unárea mínima de mapeo de 9 hectáreas $\left(90,000 \mathrm{~km}^{2}\right)$.

\subsection{Cartografía de Clasificación de la Cobertura de la Tierra de cuatro fechas}

Mediante un proceso de clasificación supervisada asignamos a cada elemento (pixel) de cada imagen del sector estudiado una clase temática. Logramos clasificar las cuatro imágenes de diferentes fechas utilizando los mismos criterios y las mismas técnicas. Los cuatro mapas temáticos mostrando la Clasificación de la Cobertura de la Tierra de un Sector Occidental de Honduras, para las fechas 1991, 1995, 2003y 2006 se muestran como Anexos A.1, A.2, A.3y A.4 respectivamente.

El porcentaje del área total ocupada por cada una de las clases por imagen fue cuantificado. Los resultados por clase por año del área de estudio se presentan en la Tabla 1. 
Tabla 1. Porcentaje de cobertura por clase, po área de estudio, por año antes y después del Mitch

\begin{tabular}{|l|c|c|c|c|}
\hline \multirow{2}{*}{$\begin{array}{l}\text { Nombre de } \\
\text { la clase }\end{array}$} & \multicolumn{2}{|c|}{ Antes de Mitch } & \multicolumn{2}{c|}{ Después de Mitch } \\
\cline { 2 - 5 } \multicolumn{1}{c|}{} & $\mathbf{1 9 9 1}$ & $\mathbf{1 9 9 5}$ & $\mathbf{2 0 0 3}$ & $\mathbf{2 0 0 6}$ \\
\hline Bosque mixto & 29.06 & 29.23 & 23.15 & 20.00 \\
\hline Arboleda de pino & 19.64 & 14.79 & 20.14 & 21.73 \\
\hline Matorral & 17.86 & 11.82 & 11.87 & 17.37 \\
\hline Pastos mixtos & 2.93 & 1.95 & 6.82 & 2.43 \\
\hline Agricultura mixta & 20.06 & 29.57 & 24.45 & 27.05 \\
\hline Urbano & 1.06 & 0.16 & 0.19 & 0.17 \\
\hline Suelo desnudo & 8.86 & 12.24 & 13.14 & 10.87 \\
\hline
\end{tabular}

Fuente: Elaboración propia.

\subsection{Comparación de valores de reflectancia obtenidos de sensores remotos y próximos}

Una imagen satelital puede ser considerada como una matriz de medidas numéricas que procesada adecuadamente permite obtener cantidades físicas de interés. Después de realizar las correcciones radiométricas, convertimos los valores de los Números Digitales registrados por el sensor remoto de LandSat en los pixeles de cada banda, en valores de reflectancia en superficie.

Luego, al realizar la clasificación supervisada del área de estudio, los pixeles de la imagen temática tomaron el valor de la clase asignada, pero guardamos como atributos de la imagen los valores estadísticos de reflectancia mínima, media, máxima y otros, para cada una de las seis bandas de la imagen original.

Esto nos permitió después, seleccionar las bandas 1, 2, 3 y 4 de LandSat comprendidas en el rango espectral del radiómetro de campo, para elaborar gráficos de reflectancia.

Para cada una de las áreas de estudio de diferentes fechas, construimos gráficos para las clases pasto mixto y agricultura mixta que presentamos en la Figuras 2-a y 2-b respectivamente. 
Figura 2-a. Reflectancia de la clase pastos mixtos obtenida de imágenes remotas LandSat

1991 - Reflectancia PASTOS

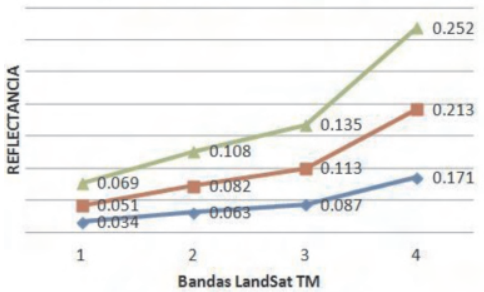

2003 - Reflectancia PASTOS

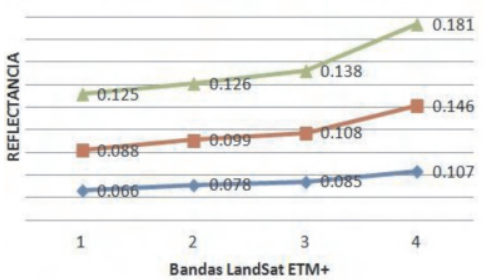

1995 - Reflectancia PASTOS

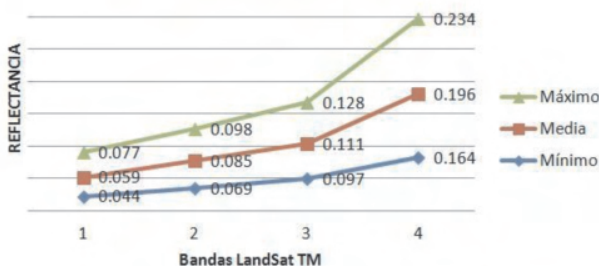

2006 - Reflectancia PASTOS

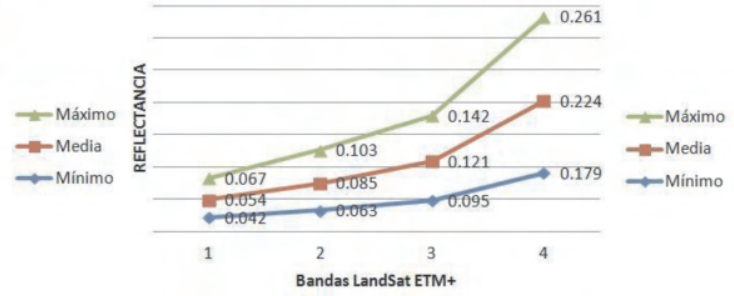

Figura 2-b. Reflectancia de la clase agricultura mixta obtenida de imágenes remotas LandSat.

1991 - Reflectancia AGRICULTURA

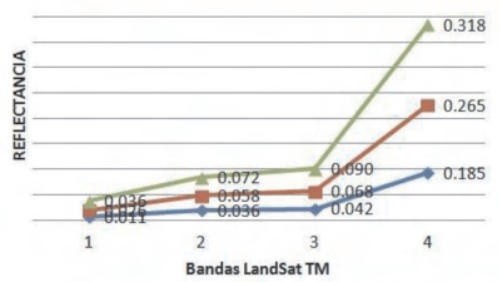

2003 - Reflectancia AGRICULTURA
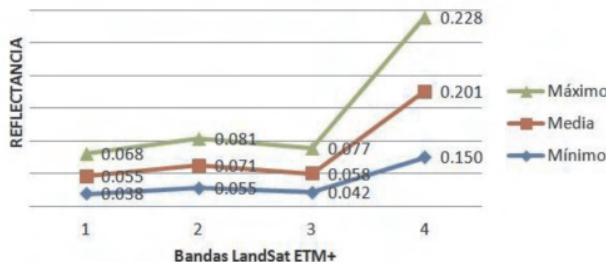

1995 - Reflectancia AGRICULTURA

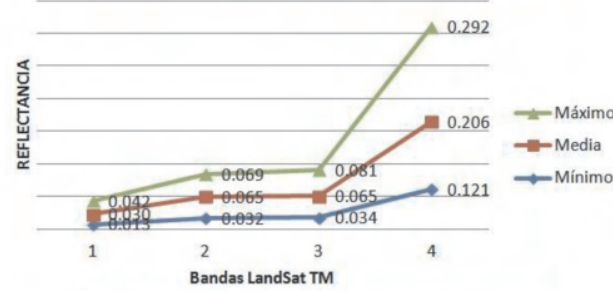

2006 - Reflectancia AGRICULTURA

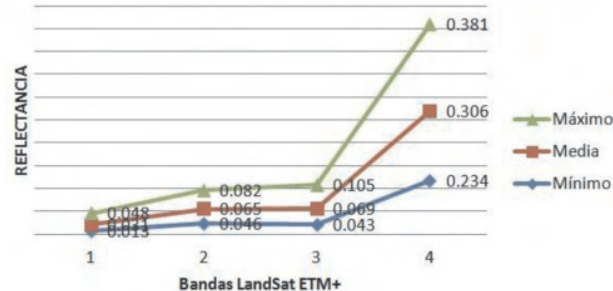


Por otro lado, utilizando el radiómetro de campo escogimos sobre la superficie de la tierra, áreas de parceles de tierra con las clases que de acuerdo con la clasificación aplicada, pertenecían a los dos tipos de cobertura de los pastos mixtos, los permanentes y los cambiantes; y en el caso de la clase agricultura mixta, a la piña y maíz seco. Con el radiómetro medimos la reflectancia de cada muestra en un rango espectral continuo entre 350 a 1075 m.

Para hacer comparables los valores continuos del radiómetro con los valores discretos de las bandas de LandSat: 1 (450 a 520 ?m), 2 (530 a 600 ?m), 3 (630 a 690 mn y 4 (760 a 900 m), tuvimos que hacer algunos cálculos. Del archivo de metadatos del radiómetro seleccionamos el rango para cada banda de LandSat; luego, ordenamos los datos por valor de reflectancia para seleccionar el valor mínimo, máximo, y calcular el valor medio.

Los resultados de los datos procesados de reflectancia del radiómetro para los rangos de las Bandas de LandSat se presentan en la Figuras 3-a y 3-b.

Figura 3-a. Reflectancia de la clase pastos mixtos obtenida por mediciones con radiómetro de campo.

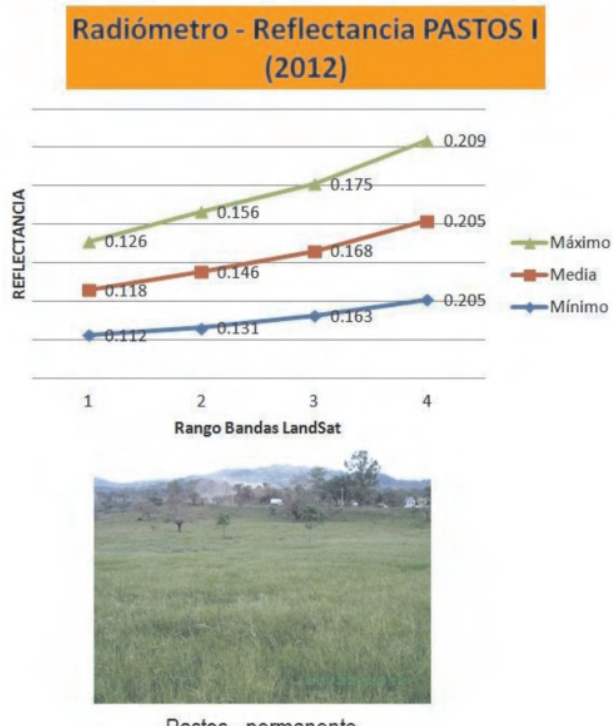

Pastos - permanente

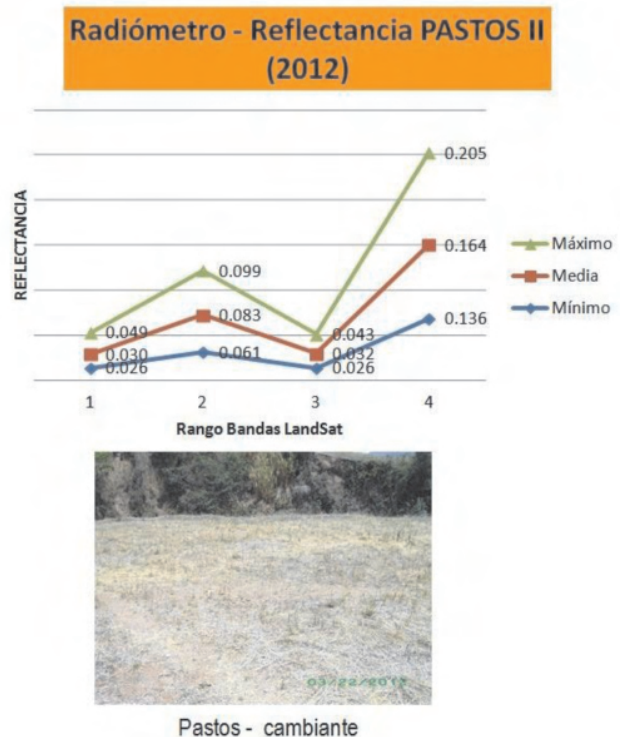

Pastos - cambiante 
Figura 3-b. Reflectancia de la clase agricultura mixta obtenida por mediciones con radiómetro de campo.

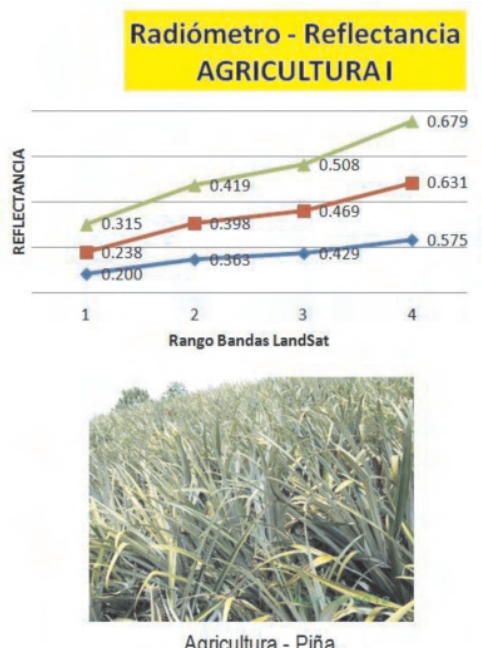

Agricultura - Piña

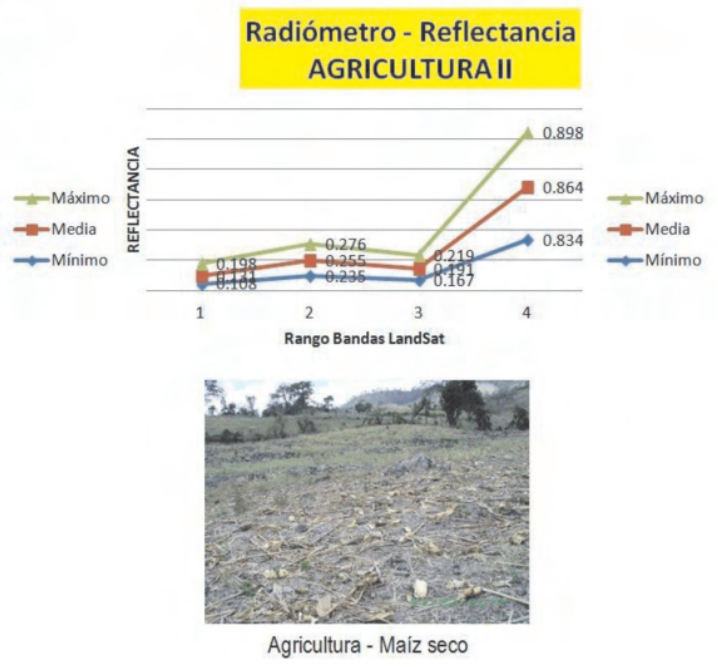

\subsection{Análisis Multitemporal y cuantificación de cambios}

Elaboramos dos mapas del cambio en la cobertura de la tierra del sector occidental de Honduras estudiado a partir de las imágenes previamente clasificadas. Uno de los mapas reflejando los cambios en las fechas antes de Mitch: 1991-1995; el otro, en las fechas posteriores a Mitch: 2003-2006. En los Anexos A.5 y A.6 se muestran estos dos mapas.

También cuantificamos las pérdidas y ganancias antes y después de Mitch. En la Figura 4 se presentan los resultados.

Figura 4. Pérdidas y ganancias detectadas como cambios antes y después de Mitch.

Antes del Huracán Mitch 1991-1995
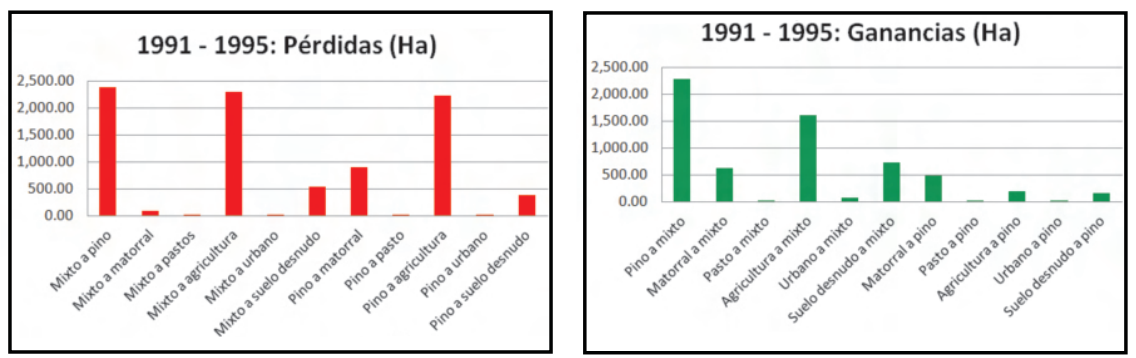

$-[96]$ Dirección de Investigación Científica 
Despues del Huracán Mitch 1991-1995
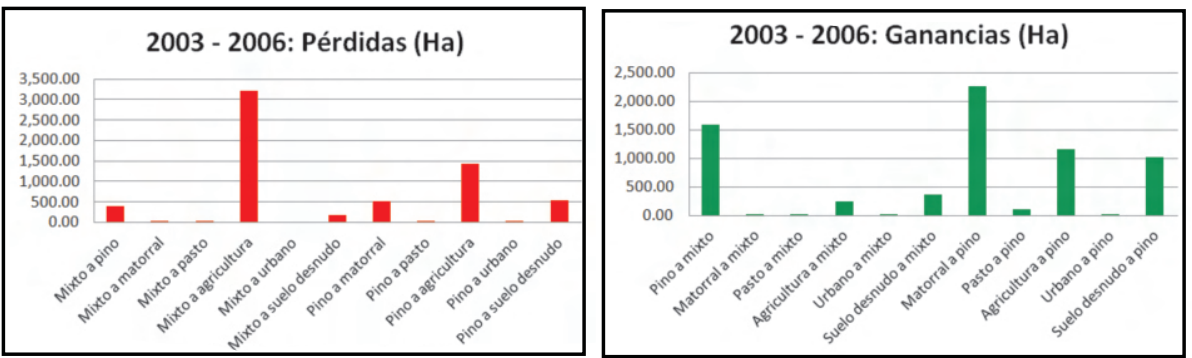

\section{DISCUSIÓN}

La percepción remota (teledetección) es una tecnología poderosa que nos ha permitido el manejo de variables biofísicas para comparar diferentes escenarios temporales; estudiar y comparar diferentes tipos de cobertura para un amplio período de tiempo, manteniendo las mismas clases y criterios de clasificación, haciéndolas entonces más confiables; detectar la dinámica de los cambios ocurridos en dos períodos de interés, antes y después de Mitch, cuantificando los incrementos y decrementos entre clases, y estudiar los de mayor incidencia. En un estudio para elaborar Cartografía de un Parque Nacional, Aldana y Bosque Sendra utilizaron el Sistema de Clasificación de Cobertura de la Tierra de FAO-UNEP (Aldana D. \& Bosque Sendra, 2008). Comentaron que este Sistema, no sólo facilita las comparaciones, sino que permite describir, sistemáticamente, las clases 0 categorías mediante la integración de un conjunto de criterios independientes desglosados en dos fases: una dicotómica que discrimina las cubiertas por la ausencia o presencia de un clasificador (presencia o ausencia de vegetación, condición edáfica (terrestre o acuática) y por la artificialidad de la cobertura (manejada o natural); y una fase modular, en la que se agregan otros parámetros para establecer con mayores detalles, los tipos de cultivos, de vegetación o de otras categorías

Para este trabajo, el uso del Sistema de Clasificación de cobertura de la tierra de FAO- UNEP permitió elaborar una leyenda con criterios precisos y sin riesgos de inconsistencias ó subjetividades. Logramos identificar siete clases de las cuales, cuatro estaban compuestas de un solo tipo de cobertura: arboleda de pino, matorrales, urbano y suelo desnudo. Las otras tres clases, estaban compuestas de dos o más tipos de cobertura reconocibles. El bosque mixto compuesto de árboles de hoja ancha y árboles de hoja acicular. Los pastos mixtos compuestos de cultivos, unos de rotación y otros permanentes. La agricultura mixta, compuesta de cultivos permanentes de arbusto, unos en plantaciones, otros en huerto u otro tipo de 
plantación, cultivos de rotación de gramíneas y de no gramíneas, y coberturas en barbecho con múltiples cultivos.

La interpretación de la cartografía y la dinámica de la clasificación de la cobertura de la tierra del sector occidental de Honduras estudiado dejan ver que:

- Las dos clases dominantes son el bosque mixto y la agricultura mixta. En los mapas de antes de Mitch, en 1991 ambas clases representaban el 50\% del área de estudio; en 1995, la cobertura del bosque mixto crece muy poco pero la agricultura mixta se incrementa casi en un 10\%, cubriendo ambas el $60 \%$ del área de estudio. En los mapas de después de Mitch, en 2003 y 2006 ambas clases cubren menos del 50\% del área estudiada, evidenciándose que el bosque mixto tiene una tendencia decreciente y la agricultura mixta una tendencia opuesta. Comparando los valores de la cobertura de ambas clases antes y después de Mitch, parece evidente que entre 1995 y 2003 ocurrió una disminución del orden del $5 \%$ en ambas clases.

- Las siguientes clases dominantes son la arboleda de pinos y los matorrales. En los mapas de 1991 y 1995, la arboleda de pino muestra una disminución de un $6 \%$, pero en los mapas de 2003 a 2006 se observa más bien un crecimiento aunque suave de un poco más de 1\%. De interés resulta comparar los mapas de 1995 y 2003 por la evidente tendencia de crecimiento estimada en un 5\%, que aparece suavizada al comparar los mapas de 2003 y 2006. Los matorrales, entre 1991 y 1995 comparados con 2003 y 2006 muestran un comportamiento completamente opuesto, en el primer período la tendencia es decreciente del orden del 6\% pero en el segundo período la tendencia es creciente por el mismo valor. Con los matorrales parece que entre los años de 1995 a 2003 la cobertura se mantuvo.

- Las clases con menores valores son el suelo desnudo, los pastos mixtos y la urbana. El mapa de 1995 muestra un porcentaje significativo de suelo desnudo provocado principalmente por el deslizamiento que se observa en el sector este de la Montaña de Celaque; llamando la atención sin embargo, que un porcentaje ligeramente mayor que el mencionado se cuantifica en el mapa de 2003, pero esta vez el suelo desnudo aparece distribuido en toda el área de estudio particularmente alrededor de los cauces de los ríos. Comparando la clase de pastos mixtos que aparece en los mapas de 1991 y 1995 antes de Mitch con los de 2003 y 2006 después de Mitch, resalta el incremento significativo del orden de 5\% entre 1995 y 2003. En todos los mapas la clase urbano prácticamente solo aparece representada en la ciudad de Santa Rosa de Copán por lo que no se puede dar seguimiento a otros asentamientos humanos. 
De acuerdo con el tamaño de cada clase, la dinámica de la cobertura de la tierra en un período de 15 años mostró que:

- Antes de Mitch el tamaño del bosque se mantuvo en un 30\%. Después, ha disminuido de $25 \%$ a $20 \%$.

- La arboleda de pinos que mostraban una tendencia decreciente antes de Mitch, de $20 \%$ a 15\%; ha revertido la tendencia, de $20 \%$ a $22 \%$, con evidentes signos de recuperación.

- También los matorrales, que antes de Mitch mostraron disminución de 18\% a 12\%, muestran una recuperación después, de 11\% a 18\%.

- La agricultura, antes y después de Mitch ha mostrado una tendencia creciente, pasando antes de $20 \%$ a $30 \%$, y después de $25 \%$ a $27 \%$. En las fechas más recientes se observa que ocupa ya no solamente la parte baja de las laderas, sino que hay intervenciones en áreas altas de bosques y de pinos.

La reflectancia fue la variable escogida para hacer comparaciones entre las mediciones obtenidas a partir del sensor remoto LandSat y las mediciones cercanas realizadas con el radiómetro campo. Dos fueron las clases estudiadas, pastos mixtos y agricultura mixta.

Las mediciones de la reflectancia de pastos mixtos obtenida de las imágenes clasificadas de LandSat de 1991(marzo), 1995(febrero) y 2006(marzo) dieron valores mínimos, máximos y medios comparables. Las mediciones de 2003(abril) mostraron valores mucho más bajos, acercándose más bien a los valores de los mínimos del resto de las imágenes.

La reflectancia de los pastos en el campo la medimos seleccionando dos tipos de parcelas. Una cuya cobertura correspondía a la clasificada como pastos permanentes, la otra a pastos cambiantes. Las curvas de reflectancia de estas coberturas reflejaron que, individualmente y promediando el valor de ambas, quedaban comprendidos dentro de los rangos medidos remotamente a partir del sensor de LandSat considerando las cuatro fechas.

Las mediciones de la reflectancia de la agricultura mixta obtenida de las cuatro imágenes clasificadas de LandSat, aunque presentaron todas unas curvas de forma comparable, el rango de los valores cubiertos fue distinto en cada caso.

La reflectancia de la agricultura en el campo la medimos seleccionando también dos tipos de parcelas. Una correspondiente a una cobertura de piñas, la otra a maíz seco. Los valores de reflectancia de estas coberturas individualmente mostraron 
valores bastante superiores a todos los rangos medidos remotamente a partir del sensor de LandSat de las cuatro fechas.

Aunque sabíamos que este tipo de comparaciones daba mejores resultados cuando los datos a comparar correspondían a las mismas o a fechas cercanas, consideramos que por la extensión del periodo estudiado la comparación podía ser de interés si nos manteníamos, por cualquier variación fenológica, dentro del mismo período del año de las tomas de cada imagen. Las imágenes de LandSat se tomaron entre el 11 de febrero y el 14 de abril; las mediciones con el radiómetro de campo las hicimos el 22 de marzo de 2012.

La interpretación espacial de la cartografía de cambios en la cobertura de la tierra del sector del occidente de Honduras estudiado, ha revelado que:

- Los decrementos ocurridos en el Período 1991-1995 quedaron distribuidos en toda el área de estudio; limitándose, en el Período 2003-2006 principalmente a las laderas de la Montaña de Celaque en zonas reconocidas de mayor cobertura de bosques mixtos.

- Los incrementos ocurridos en el Período 1991-1995 se concentran principalmente en zonas reconocidas con cobertura de bosque mixto y arboledas de pinos en la parte sur de la imagen. En el Período 2003-2006 los incrementos, aunque concentrados en la parte noreste y noroeste de la imagen, corresponden principalmente a zonas reconocidas con cobertura de arboleda de pinos y matorrales.

- $\quad$ Las zonas sin cambio, tanto en el Período 1991-1995 como en el de 20032006 se localizan principalmente, a uno y otro lado de las márgenes de los ríos correspondiendo en ambos casos a parcelas agrícolas de mediano a gran tamaño bien delimitadas, a la mancha urbana de Santa Rosa de Copán, y al sector norte de la zona núcleo del Parque Nacional de Celaque.

En la cuantificación de los cambios se ha revelado que:

- Antes de Mitch en el Período 1991-1995, perdidas un poco mayores de 2,000 hectáreas se han notado principalmente de bosque mixto a pino, de bosque mixto a agricultura y de pino a agricultura. En cambio las ganancias se han notado, también en unas 2,000 hectáreas, por la recuperación de pino a bosque mixto; y en una menor cantidad, unas 1,500 hectáreas, de agricultura a bosque mixto poniendo en evidencia la forma de cultivo de rotación 0 cambiante relacionada con las prácticas culturales que se detectó con el Sistema de Clasificación. 
- Después de Mitch en el Período 2003-2006 sobresalen las pérdidas por el cambio de bosque mixto a agricultura en más de 3,000 hectáreas, y de pino a agricultura en unas 1,500 hectáreas. Las ganancias se observan en unas 1,500 hectáreas de pino a bosque mixto, más de 2,000 hectáreas de matorral a pino, 1,000 hectáreas de agricultura a pino y otras 1,000 hectáreas de suelo desnudo a pino, poniéndose en evidencia que en esta zona de estudio, para el período estudiado ha habido una recuperación del bosque.

En el área estudiada, a la escala seleccionada, los principales cambios detectados han ocurrido entre las clases de bosque mixto, arboleda de pino, agricultura mixta y matorrales. Los cambios en la clase urbana, si los hubo, no fueron apreciablemente detectados.

\section{CONCLUSIONES}

Al haber estudiado la cobertura de la tierra de un sector occidental de Honduras, en un período amplio de quince años, utilizando las mismas técnicas de clasificación en cuatro fechas diferentes hemos podido detectar:

1. El marcado avance de la frontera agrícola a expensas de la disminución de la cobertura de bosques del sector. La agricultura se extiende más allá de las laderas, internándose en la zona de bosques.

2. La agricultura practicada en el sector estudiado es mixta, no solamente en cuanto al tipo de cultivos, sino por las prácticas culturales. Una parte de las zonas agrícolas se presentan como zonas de no cambio, más permanentes. Otras, las que usan prácticas más tradicionales, se muestran como decrementos, al cambiar continuamente el tipo y los lugares de cultivo.

3. Estos cambios estuvieron acompañados por la recuperación del bosque, manifestándose como incrementos, especialmente de arboledas de pino a partir de coberturas de matorrales, pastos y suelo desnudo.

4. Por la escala estudiada, los patrones de asentamiento humano, más allá de la mancha urbana de Santa Rosa de Copan no se han podido detectar.

5. Más que el impacto de Mitch en la zona estudiada, lo que se detectó fue la pervivencia de sus efectos, reflejada por alteraciones de la cobertura vegetal de los patrones agrícolas y algunos efectos de regeneración de los bosques, arboledas de pino y matorrales.

\section{AGRADECIMIENTOS}

Agradecemos a la Dirección de Investigación Científica de la Universidad Nacional 
Autónoma de Honduras por habernos otorgado la Beca Sustantiva No. 01-BSI2007, que hizo posible la realización de este trabajo. A los profesores del Centro Universitario Regional de Occidente (CUROC) de la Universidad Nacional Autónoma de Honduras, por habernos acompañado en nuestras giras de campo al occidente de Honduras.

\section{BIBLIOGRAFÍA}

Agencia Europea del Medio Ambiente. (1995). Instituto Geográfico Nacional de España. Recuperado el julio de 2012, de Ocupacion del suelo: Proyecto Corine Land Cover (CLC):

\section{http://www.02.ign.es/ign/layoutln/corineLandCover.do}

Aldana D., A. T., \& Bosque Sendra, J. (2008). Cartografía de la cobertura/uso de la tierra del Parque Nacional Sierra de La Culata, estado Mérida-Venezuela. Revista Geográfica Venezolana, Vol. 49(2), 173-200.

Analytical Spectral Devices, Inc. (2003). FieldSpec(R) UVNNIR -HandHeld Spectroradiometer - User's Guide. Boulder, Colorado, United States of America:ASD Inc.

Anderson, J. R., Hardy, E. E., Roach, J. T., \& Witmer, R. E. (1976). A Land Use and Land Cover Classification System for use with Remote Sensor Data. U. S. Geological Survey Circular 671, 1-27.

Arquero, A., Martínez, E., \& Gonzalo, C. (2003). Reducción de datos hiperespectrales de radiometría de campo. En R. Pérez Utrero, \& P. Martínez Cobo, Teledetección y Desarrollo Regional. X Congreso de Teledetección (págs. 439-442). Cáceres, España.

Chuvieco Salinero, E. (2008). Teledetección Ambiental. La observación de la Tierra desde el Espacio. Barcelona, España: Ariel, Ciencias.

Di Gregorio, A. (2005). Land Cover Classification System. Classification concepts and user manual. Roma, Italia: Food and Agriculture Organization of the United Nations (FAO).

Guiney, J. L., \& Lawrence, M. B. (1999). Hurricane Mitch, 22 October - 05 November 1998. Miami, U. S. A.: National Hurricane Center.

Leica Geosystems. (2012). Leica Geosystems. Recuperado el Agosto de 2012, de ERDAS User Manual: C:ILeica Geosystems|Geospatial Imaging9.21 helplwwhelplwwhimplljs/htmllwwhelp.htm

Pineda Portillo, N. (2008). Geografía de Honduras, 4ta. Edición. Tegucigalpa, Honduras: Multigráficos Flores S. de R. L.

Programa de las Naciones Unidas para el Desarrollo (PNUD). (1998). Informe sobre Desarrollo Humano 1998. Castello, España: Mundi-Prensa Libros, S. A. Programa de las Naciones Unidas para el Desarrollo (PNUD). (2006). Informe sobre 
Desarrollo Humano 2006. México D. F.: Mundi-Prensa México S. A. de C. V. Programa de las Naciones Unidas para el Desarrollo Honduras. (2006). Programa de las Naciones Unidas para el Desarrollo Honduras. Recuperado el julio de 2012, de Informe Nacional de Desarrollo Humano 2006: http://www.undp.un.hn/pub_indh_2006.htm

Programa de las Naciones Unidas para el Desarrollo Honduras. (1998). Programa de las Naciones Unidas para el Desarrollo, Honduras. Recuperado el julio de 2012, de Informe Nacional de Desarrollo Humano 1998: http://www.undp.un.hn/pub_indh_1998.htm

Sistema de Información de Biodiversidad. (2005). Protocolo para el preprocesamiento de imágenes satelitales LandSat para aplicaciones de la Administración de Parques Nacionales. Buenos Aires, Argentina: Administración de Parques Nacionales.

United States Geological Survey. (2012). Earth Resources Observation and Science Center. Recuperado el 2007, de USGS Global Visualization Viewer: http://glovis.usgs.gov

United States Geological Survey, USGS. (Agosto de 2012). USGS Home Geographical Analysis and Monitoring Program. Recuperado el Agosto de 2012, de AChanging Planet: http://gam.usgs.gov/

\section{ANEXOS}




\section{Anexo A1}

\section{MAPA DE LA CLASIFICACION DE LA COBERTURA DE LA TIERRA DE UN SECTOR OCCIDENTAL DE HONDURAS \\ Año: 1991}

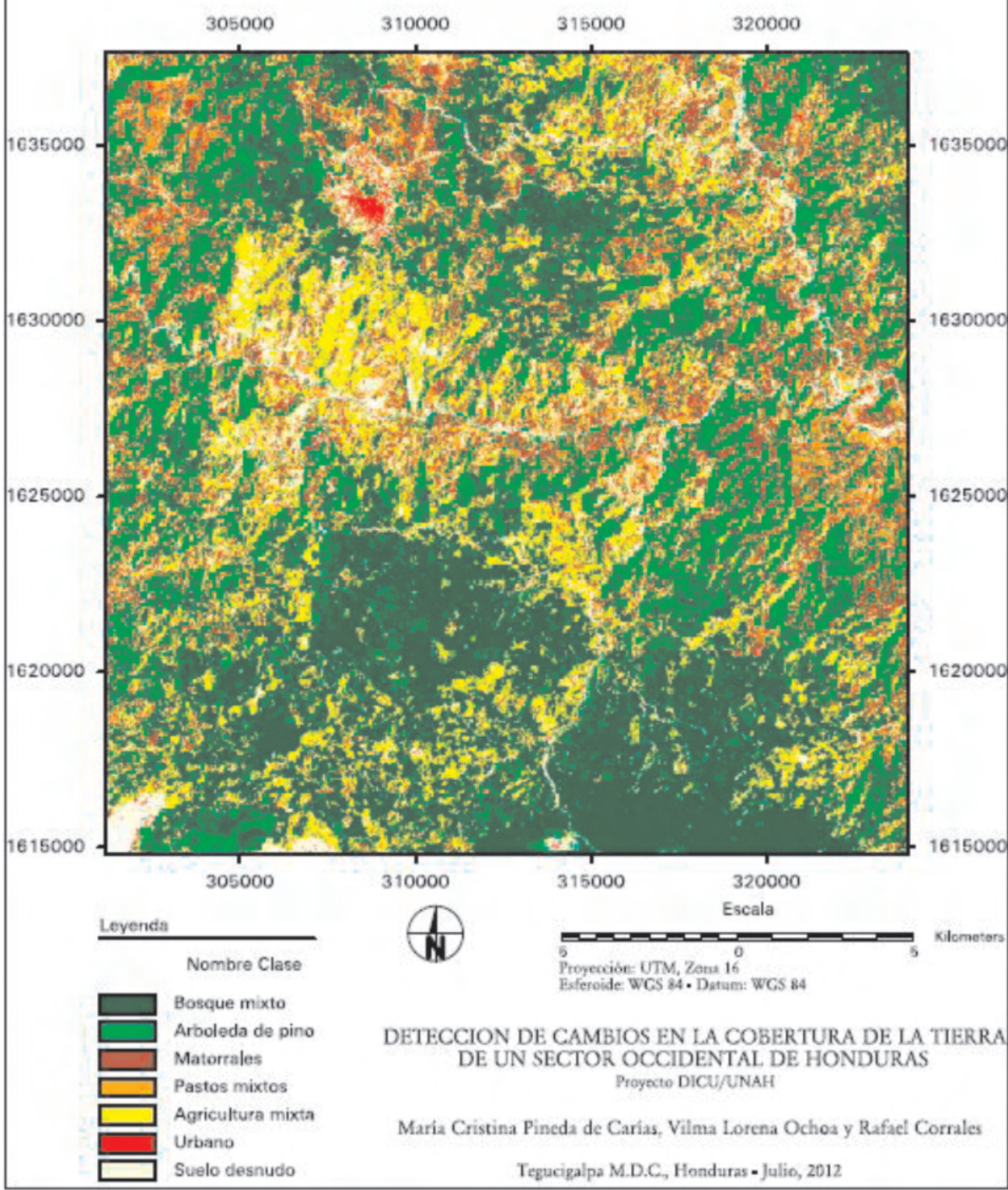




\section{Anexo A2}

\section{MAPA DE LA CLASIFICACION DE LA COBERTURA DE LA TIERRA DE UN SECTOR OCCIDENTAL DE HONDURAS \\ Año: 1995}

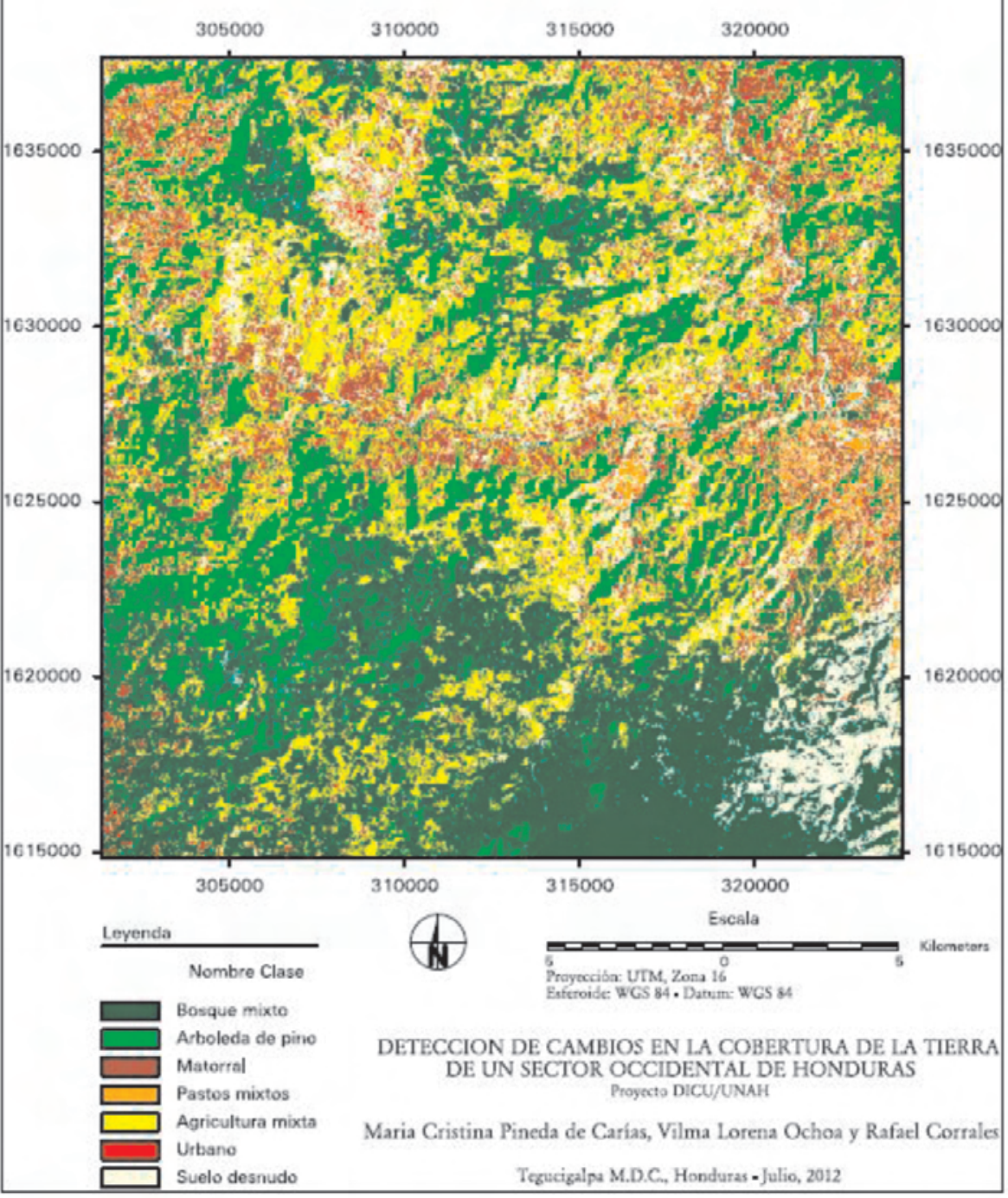




\section{Anexo A3}

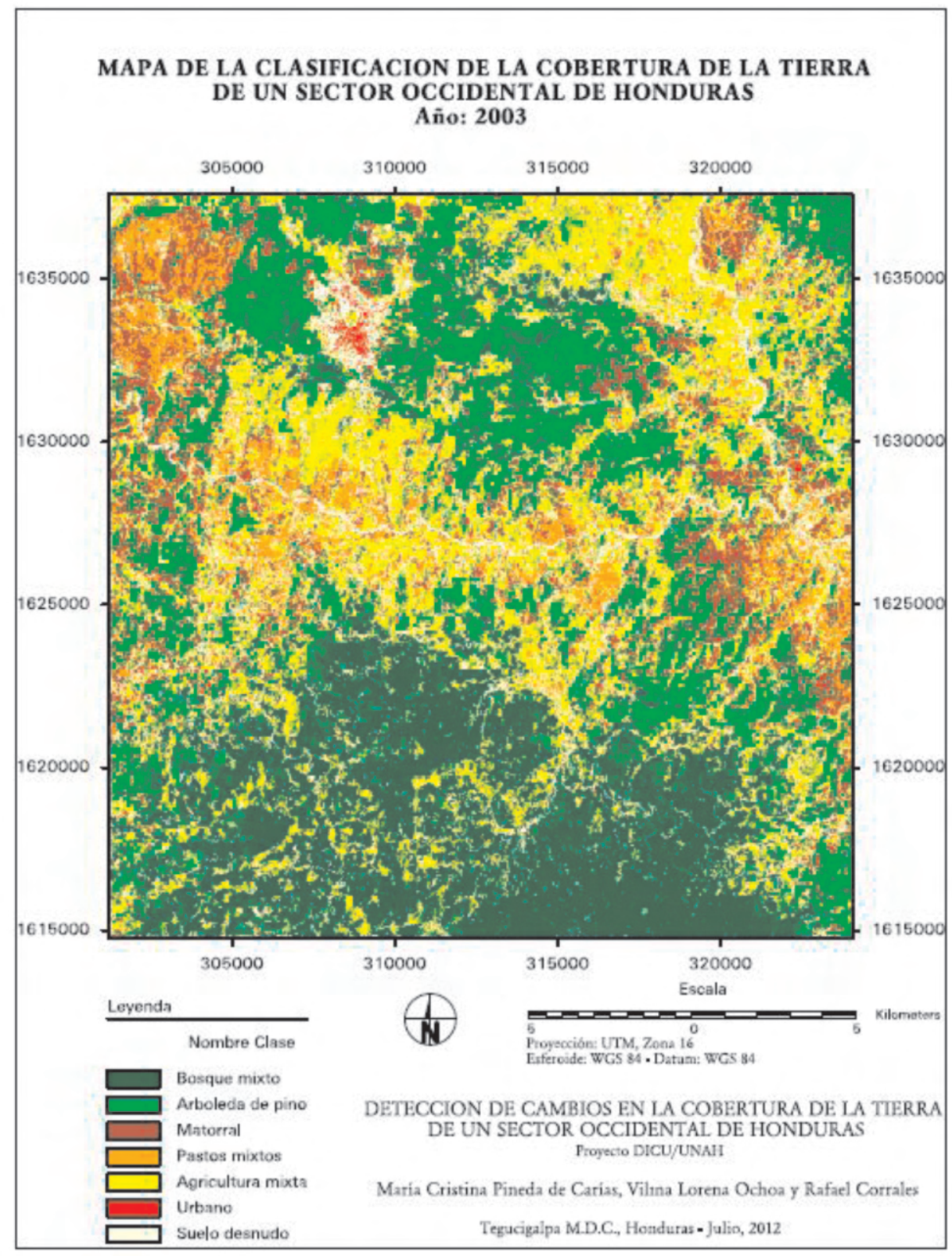




\section{Anexo A4}

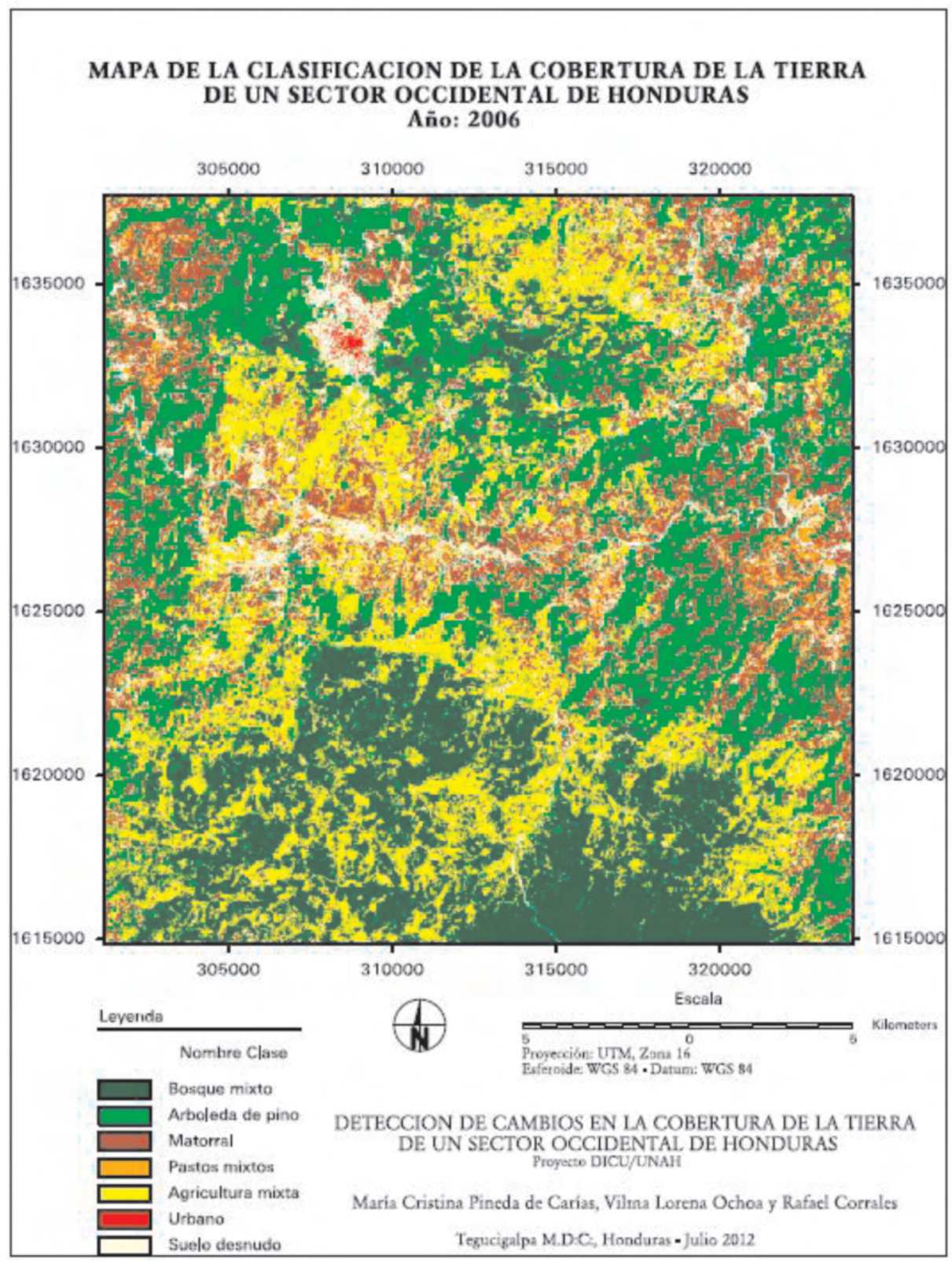




\section{Anexo A5}

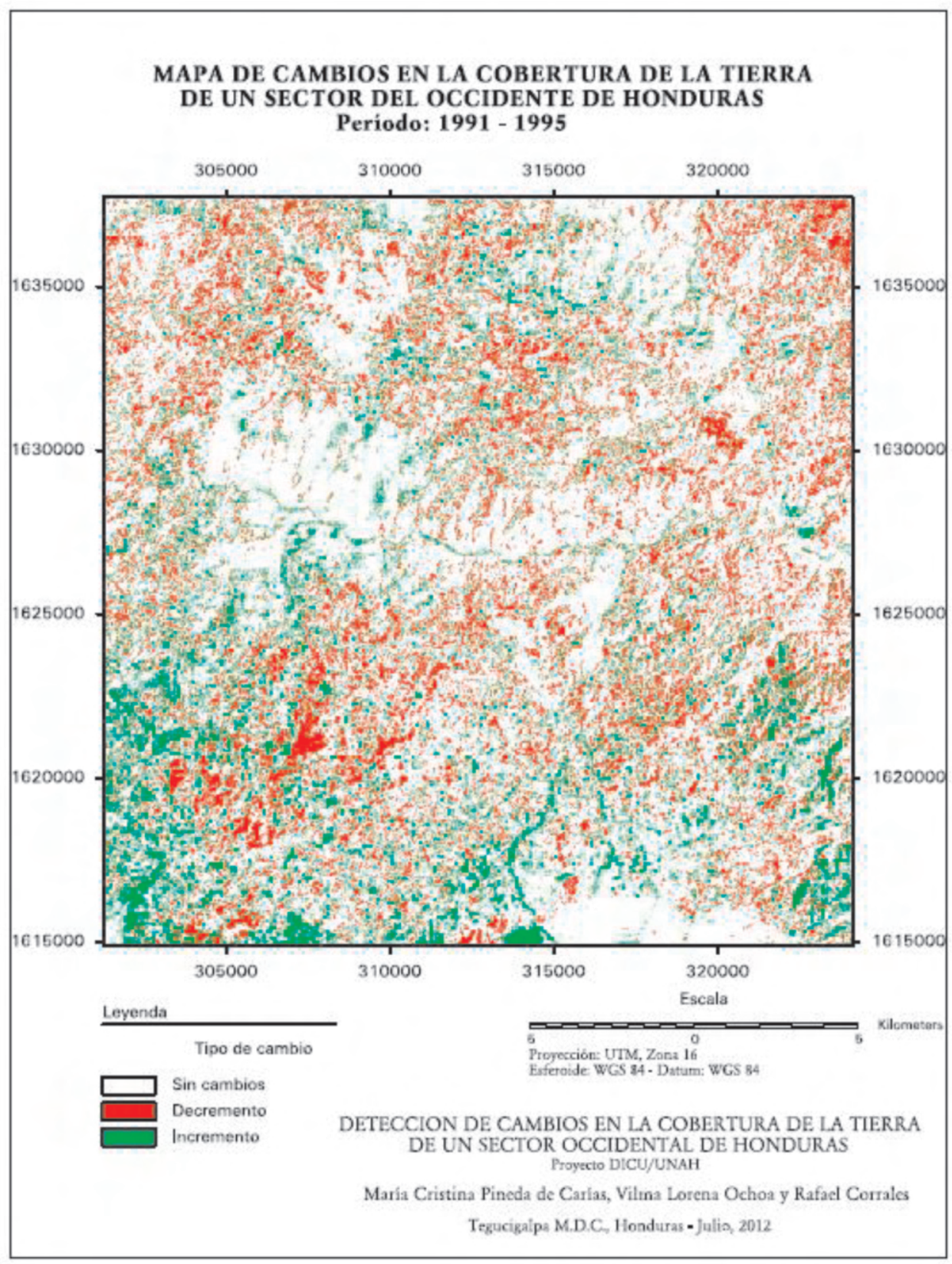




\section{Anexo A6}

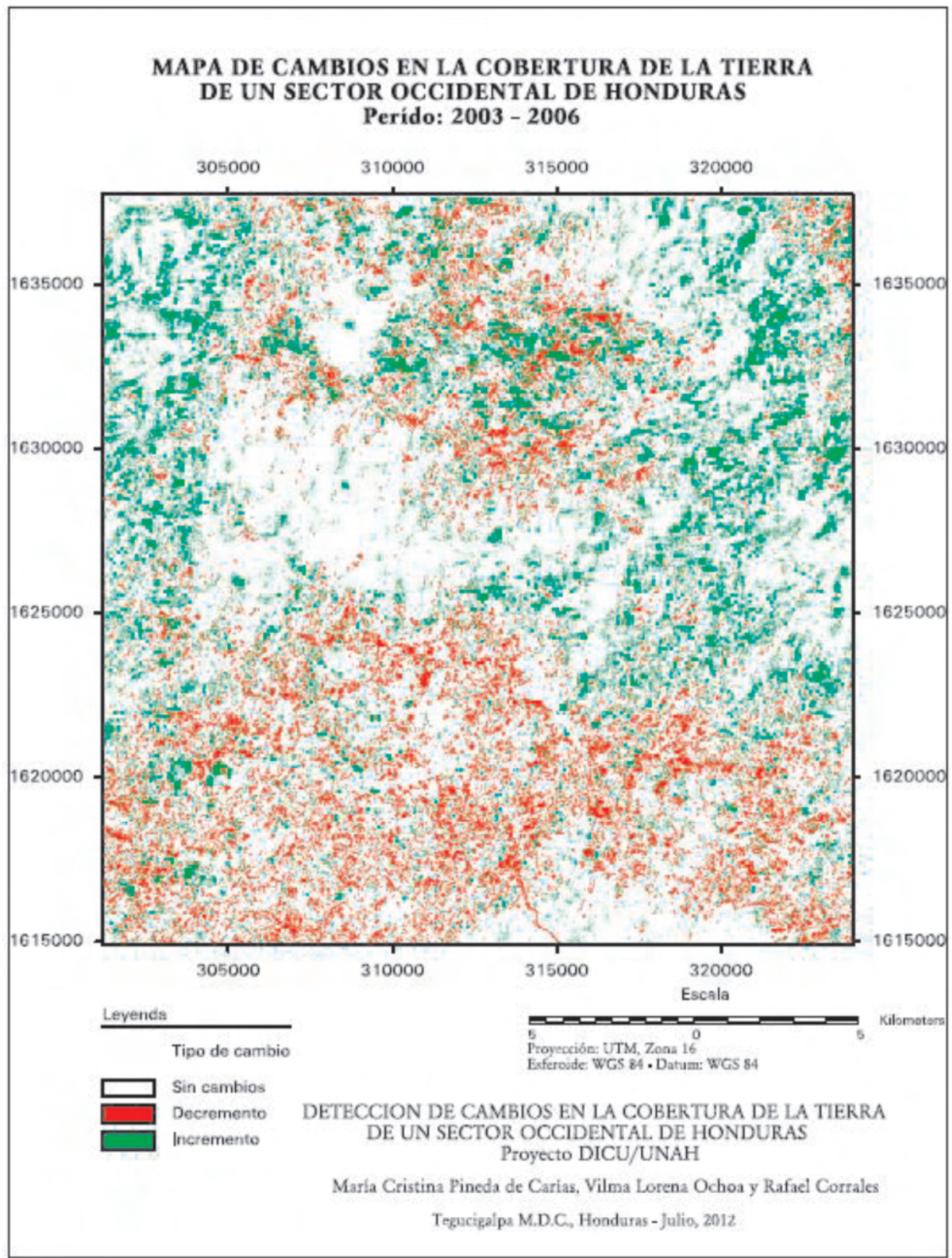

